Fåhraeus, G. (1957). J. gen. Microbiol. 16, 374-381

\title{
The Infection of Glover Root Hairs by Nodule Bacteria Studied by a Simple Glass Slide Technique
}

\author{
By GÖSTA FÅHRAEUS \\ Institute of Microbiology, Royal Agricultural College, \\ Uppsala 7, Srweden
}

SUMMARY: A simple glass slide technique has been devised for the continuous microscopical observation of growth and infection of root hairs of clover seedlings. The method involves an aseptic cultivation of seedlings on microscope slides which are partly immersed in a mineral salts medium. The roots are protected by a coverslip.

By this procedure, the root hairs of white clover inoculated with nodule bacteria were studied. The earliest infection was observed to take place within $48 \mathrm{hr}$. of inoculation, on 4-day-old seedlings. In branched hairs the growth of the thread from a lateral branch towards the hair tip is tentatively explained as an effect of the position of the hair nucleus relative to the site of infection.

The infection of leguminous plants by nodule bacteria has, as a rule, been studied with fixed and sectioned material. The first stages of this process may also be studied in vivo, but no suitable technique has yet been described for a continuous microscopical examination of these stages.

A method for the study of growing root hairs (of wheat) was devised by Lundegårdh (1946) and modified by Ekdahl (1953). In their work, a chamber containing flowing salt solution and resting on a microscope stage was employed. However, difficulties arise with this method if aseptic conditions are also necessary. The present author has therefore used a technique for the aseptic cultivation of young seedlings on microscope slides in a manner which permits periodic observations under the microscope of the growth and infection of individual root hairs. The arrangement also offers good conditions for photomicrography.

The details of the method are as follows.

\section{METHOD}

A nitrogen-free mineral solution of the following composition was prepared: $\mathrm{CaCl}_{2}, 0 \cdot 1 \mathrm{~g}$.; $\mathrm{MgSO}_{4} \cdot 7 \mathrm{H}_{2} \mathrm{O}, 0 \cdot 12 \mathrm{~g}$. $; \mathrm{KH}_{2} \mathrm{PO}_{4}, 0 \cdot 1$ g. ; $\mathrm{Na}_{2} \mathrm{HPO}_{4} \cdot 2 \mathrm{H}_{2} \mathrm{O}, 0 \cdot 15$ g. ; Fe citrate, 0.005 g.; $\mathrm{Mn}, \mathrm{Cu}, \mathrm{Zn}, \mathrm{B}$, Mo traces; dist. water, $1000 \mathrm{ml}$.; pH 6.5 (after autoclaving).

Portions $(25 \mathrm{ml}$.) of this solution were distributed into large glass tubes $(39 \times 125 \mathrm{~mm}$.). The tubes were plugged with cotton wool or covered with closely fitting glass caps $(45 \times 60 \mathrm{~mm}$.) and were sterilized in the autoclave for $20 \mathrm{~min}$. at $120^{\circ}$ (15 lb./sq.in.). Microscope slides $(26 \times 75 \mathrm{~mm}$.) and cover-slips $(24 \times 40 \mathrm{~mm}$.) were sterilized by heating dry in Petri dishes, preferably only one slide and one cover-slip in each dish. 
Seeds of white clover (Trifolium repens, variety Morsö, from Svalöf, Sweden) were disinfected by successive treatment with $95 \%$ ethanol and equal parts of $0 \cdot 2 \%$ formaldehyde and $0 \cdot 2 \% \mathrm{HgCl}_{2}$ and were then washed in several changes of sterile water. They were allowed to germinate at room temperature in a shallow layer of water.

After 2 days, when the seedlings were $10-15 \mathrm{~mm}$. in length, they were transferred to the glass slides in the following manner: 6-7 drops $(c .0 \cdot 2 \mathrm{ml}$.) of $0 \cdot 3-0.4 \%$ Bacto agar in the above-mentioned mineral solution, previously melted and cooled to $c .30^{\circ}$, were pipetted over one half of each slide, and immediately thereafter a seedling was taken with a platinum wire and placed on the slide with the root tip in the agar. 'The cover-slip was then laid carefully over the agar and the root by means of sterile forceps. The seed coat was removed, if it still adhered to the cotyledons. When all slides were prepared, they were transferred from the dishes into the tubes containing mineral solution.

As a rule, inoculation was made with a few drops of a thick suspension of young Rhizobium trifolii (local strain No. 220) added to the solution in the tubes. When rapid infection was desired, the agar was inoculated before making up the slides. All manipulations were made aseptically with sterile instruments in a sterile room.

The tubes were placed in a constant temperature room at $25^{\circ}$ under a fluorescent lamp. For convenient handling the tubes were kept in a metal rack (in which they were also sterilized).

For the microscopic examination, the slides were taken from the tubes with forceps and excess solution drained off carefully with filter-paper. As an immersion liquid for the high-power objective glycerol instead of ordinary immersion oil was used, since it is easier to rinse off in water. After the examination, the slides were put back into their tubes.

For the observation of living plants and bacteria, the phase contrast equipment was employed. This facilitated the study of bacterial motion and protoplasmic streaming and enabled the nuclei and other structures of the root hairs to be readily observed, particularly in the longer hairs, at some distance from the main root.

Stained preparations were made by lifting off the cover-slip and immersing the slide in the dye solution for a suitable period of time. After this the root was covered with some drops of nutrient solution and a new cover-slip applied. As a rule, the root hairs earlier studied in vivo were easily found on renewed examination.

In the microscopic work, a Zeiss Lumipan microscope with a graduated mechanical stage was used. Photomicrographs were taken with the aid of a Busch Akaflax camera provided with $9 \times 12 \mathrm{~cm}$. glass plates, using Kodak O 120 plates.

The technique outlined above is simple and requires no special equipment. Its chief advantage is the possibility of making continuous observations on the development of the root hairs and on the activity of the infecting bacteria without disturbing the root system.

Some definite limitations of the technique should be pointed out. First, the 
method is only suitable for small seedlings. Further, although initially under aseptic conditions the slides are intermittently exposed to air-borne bacteria and moulds. Experience has shown, however, that contaminating microorganisms do not appear in the microscopic fields until many days after the first examination. This is probably because the medium is unsuitable for the rapid growth of most contaminants.

A third objection which might be put forward is that the limited space between the slide and coverslip does not permit as luxuriant a growth of the plant as under ordinary culture conditions. The development of individual root hairs is naturally affected by their position relative to the glasses. Any hair reaching the glass will be more or less deformed, and it is important to distinguish this merely physical deformation from that caused by infection.

\section{RESULTS}

With the method just described, the growth of seedlings of white clover was examined. The main results may be summarized as follows.

\section{Time of infection}

In experiments with lucerne plants, Thornton $(1929,1954)$ found that the infection, as manifested by the appearance of the first nodule, coincided with the opening of the first true leaf. This also holds true for clover (Chen \& Thornton, 1940), but not necessarily for other plants. For example, Bieberdorf (1938) found no such correlation in soybeans. In red clover, Nutman (1946, 1953,1956 ) observed much genetically-determined variation in this respect. In early nodulating strains, he obtained nodulation when the seedlings were 10-15 days old. Clearly in these cases the actual infection must precede nodulation by one or more days; however, Chen \& Thornton (1940) remark that 'Nodules... appeared on the same day in which infected root hairs were first observed'.

In the writer's experiments also, great variation with regard to time for infection was observed. This is probably sufficiently explained by the heterogeneity of the plant material. In many plants, an infection of the root hairs was observed on the second day following inoculation (4 days after germination of the seed), at which time only the cotyledons had developed, whereas in other plants no infection was observed until the tenth day.

On the other hand, nodulation was never observed until 7-8 days after inoculation, even if root hair infection had occurred as early as on the second day. This may mean that the penetration of the root tissue required more time in these experiments than in those reported by Chen \& Thornton. In confirmation of earlier experience, it was found that only a small proportion of the root hairs (less than $2 \%$ ) became visibly infected.

\section{Association of the rhizobia with the root hairs}

Before infection, some sort of attachment of the nodule bacteria to the root hair surface may be expected. However, there was never any conspicuous accumulation of bacteria on those root hairs which were visibly infected. The 
invasion of nodule bacteria between the root hairs could easily be followed in the microscope. These showed vigorous motility, but very few became attached to the hairs. Bacterial masses like the one pictured by, for example, Viermann (1929) could only be seen in old stages.

Other workers have observed small clumps of nodule bacteria attached to the root hairs (Thornton, 1936, in lucerne), which were again larger than the colonies observed at the tip of infected clover root hairs in the present investigation. The latter were only seen at the tip of some straight infected hairs, where no curling prevented the examination, and consisted of a few minute rods. The exact size of these rods has not been determined, but certainly their thickness did not exceed $0 \cdot 2 \mu$. Careful examination failed to show any rods of ordinary size at the point of infection.

In summary, it seems that a very restricted number of minute bacteria attack the root hairs and become the infecting agents. The probable importance of such small rods in the infection process was clearly recognized in the early work of Beijerinck (1888) and has also been commented upon recently by Nutman (1956).

\section{Mechanism of entry}

Several workers have observed a 'brilliant spot' and/or a 'bladder-like swelling' at the site of infection (Ward, 1887; Prazmowski, 1890; Dawson, 1900; Viermann, 1929). A more or less pronounced bud-like outgrowth, sometimes highly refractile, has frequently been noted also in the present investigagation (Pl. 1, fig. 2, 3).

As an interpretation of this structure, it might be suggested that the nodule bacteria cause a local weakening of the cell wall, whereupon the osmotic pressure of the cell sap forces the wall to expand. This requires some kind of enzymic action, and although the thorough investigation of McCoy (1932) failed to demonstrate the production of cell-wall dissolving enzymes by the bacteria, this question is not yet finally settled. The possibility that the root hairs, in response to some stimulation by the bacteria, locally secrete an enzyme facilitating the penetration might also be considered. This idea seems to deserve some attention, especially since Neely, Ball, Hamner \& Sell (1950) and Bryan \& Newcomb (1954) have shown that the pectin methylesterase activity of some plant tissues is increased by auxins, for instance indole acetic acid, which is believed to be produced by nodule bacteria (Thornton \& Nicol, 1936; Thimann, 1936; Chen, 1938; Georgi \& Beguin, 1939).

\section{The infection thread}

There is general agreement that the nodule bacteria pass down the root hairs within an infection thread. This structure has always aroused the interest of those studying the interaction between nodule bacteria and legumes. Although this thread was observed and depicted by early investigators such as Eriksson (1874), Ward (1887) and Prazmowski (1890) its real nature and functioning is still debated, which is evident from the discussion of this subject 
in the recent survey of Nutman (1956). The appearance of the infection thread as seen with phase contrast is shown in Pl. 1, fig. 4-6 and Pl. 2, fig. 7,8 .

The site of infection is always characterized by an intense plasmatic activity, the cell protoplasm and the cell nucleus being concentrated to this region (Pl. 1, fig. 4 and Pl. 2, fig. 7). This activity may be observed before any infection thread is visible, and it seems probable that the infection has then taken place, although no rigid thread structure has been formed (Pl. 3, fig. 13). The host plant may react by forming a transverse cell wall, although this does not prevent the further growth of the infection thread (Pl. 1, fig. 4-6).

From Pl. 2, fig. 7, it is evident that the tip has a round shape, a fact which is very difficult to establish with bright field illumination owing to the thick layer of protoplasm surrounding the tip. This may explain why early investigators like Frank (1890) and Dawson (1900) believed the end to be 'open'.

In the root hairs examined there was rarely more than one infection thread in each hair. Two threads were seen occasionally similar to those pictured by Bieberdorf (1938) in soybeans, but multiple threads as described by McCoy (1929) in Phaseolus were never encountered.

The growth rate of the infection threads varied to some extent. In some plants it was determined at a rate of between 5 and $8 \mu$. $/ \mathrm{hr}$. With a root hair length of $100-200 \mu$., this would mean that an infection thread reaches the base of the hair within one day or slightly more. This result seems to agree with earlier observations on various legumes. As mentioned above, nodule formation was always delayed for many days.

Frequently, the growth of the infection threads stopped at an early stage (Pl. 1, fig. 5, 6). The proportion of unsuccessful threads is difficult to establish but was seldom less than 10-20\%.

Early investigators reported the occurrence of numerous bacterial rods within the infection threads (Prazmowski, 1890; Dawson, 1900; later Bieberdorf, 1938), while some more recent work suggests the existence of a single line of bacteria only (McCoy, 1929; Schaede, 1940). These observations were made on fixed and stained material, because it is almost impossible in unstained preparations to distinguish the bacteria from particles in the protoplasm surrounding the thread. This applies equally to observation with phase contrast, although the bacteria outside the root hairs are easily observed (Pl. 2, fig. 8).

After staining with suitable dyes the infection threads appear granular (Pl. 2, fig. 9). It is, however, doubtful whether all the minute stained particles are bacteria. The investigations of McCoy (1932) and Schaede (1940, 1941) have given convincing evidence that the infection thread soon becomes enclosed within a sheath of cellulose which, at least at the time of formation, is covered by a layer of living protoplasm. In living preparations small protoplasmic granules may be seen moving along the thread surface, and, in the present writer's opinion, most of the minute particles in stained preparations are on the outside of the thread. 


\section{Infection of branched root hairs}

It was frequently observed in the course of the present work that infection threads were initiated in a branch or a bulb emerging from the side of a root hair, sometimes rather close to the base of the hair. It has not been definitely established whether such hairs have been infected at an early stage and then a new tip has been formed or whether the branches are themselves formed on fully grown hairs.

The infection threads originating in a side branch normally grow into the main part of the hair and turn down into the hair base. In many instances, however, such threads grew in the opposite direction, towards the apex of the hair (Pl. 2, fig. 10-11 and Pl. 3, fig. 12, 14). Such threads often ceased their growth before reaching the hair apex (Pl. 2, fig. 10), but occasionally a thread would turn near the tip and then grow back through the entire hair and disappear into the root tissue. In such cases double threads could be seen in the apical part of the hair, one ascending and one descending (Pl. 2, fig. 11).

An influence from the cell nuclei on the infection threads penetrating the root cortex was supposed by Beijerinck (1888). This was confirmed later by some authors (Dangeard, 1926; Schaede, 1940), but has been questioned by others (Dawson, 1900).

Observations of infection threads in branched hairs strongly suggested that the growth of the thread towards the hair tip was due to directing influence of the host cell nucleus. Abnormal threads were nearly always associated with the occurrence of the nucleus in the apical part of the hair (Pl. 3, fig. 12-14) whereas normal basipetal growth was associated with the location of the nucleus in the basal part of the hair. The very few exceptions to this rule were no doubt due to movement of the nucleus subsequent to the completion of growth of the infection thread.

It appears that when growth in a certain direction is once initiated, the infection thread follows a straight course which is independent of slight fluctuations in the position of the nucleus. Some observations indicate that the nucleus may degenerate and assume a round shape as a result of the action of the infection thread.

The skilful assistance of $\mathrm{Mr} \mathrm{O}$. Forsberg in some of the photographic work is gratefully acknowledged.

\section{REFERENCES}

Beijerinck, M. W. (1888). Die Bacterien der Papilionaceen-Knöllchen. Bot. Ztg., $46,725,757$.

Bieberdonf, F. W. (1938). The cytology and histology of the root nodules of some Leguminosae. J. Amer. Soc. Agron. 30, 375.

Bryan, W. H. \& Newcomb, E. H. (1954). Stimulation of pectin methylesterase activity of cultured tobacco pith by indoleacetic acid. Physiol. Plant. 7, 290.

Chen, H. K. (1938). Production of growth substance by clover nodule bacteria. Nature, Lond. 142, 753.

Chen, H. K. \& Thonnton, H. G. (1940). The structure of 'ineffective' nodules and its influence on nitrogen fixation. Proc. Roy. Soc. B, 129, 208. 
Dangeard, P. A. (1926). Recherches sur les tubercules radicaux des Légumineuses. Botaniste, 16, 1.

Dawson, M. (1900). Nitragin and the nodules of leguminous plants. Phil. Trans. B, $192,1$.

EkDAHL, I. (1953). Studies on the growth and the osmotic conditions of root hairs. Symb. bot. upsaliens. 11, 6.

ERIKsson, J. (1874). Studier öfver Leguminosernas rotknölar. Dissertation. Lund.

Frank, B. (1890). Über die Pilzsymbiose der Leguminosen. Berlin: Parey.

Georgi, C. E. \& Beguin, A. E. (1939). Heteroauxin production by efficient and inefficient strains of rhizobia. Nature, Lond. 143, 25.

LUNDEGÅRDH, H. (1946). The growth of root hairs. Ark. Bot. 33 A, 5.

McCoy, E. (1929). A cytological and histological study of the root nodules of the bean, Phaseolus vulgaris L. Zbl. Bakt. (II), 79, 394.

McCoy, E. (1932). Infection by Bact. radicicola in relation to the microchemistry of the host's cell walls. Proc. Roy. Soc. B, 110, 514.

Neely, W. B., Ball, C. D., Hamner, C. L. \& Sell, H. M. (1950). Effect of 2,4dichlorophenoxyacetic acid on the invertase, phosphorylase and pectin methoxylase activity in the stems and leaves of the red kidney bean plants. Plant Physiol. 25, 525.

Nutman, P. S. (1946). Genetical factors concerned in the symbiosis of clover and nodule bacteria. Nature, Lond. 157, 463.

Nutman, P. S. (1953). Studies on the physiology of nodule formation. IV. The mutual inhibitory effects on nodule production of plants grown in association. Ann. Bot., N.S. 17, 95.

Nutman, P. S. (1956). The influence of the legume in root-nodule symbiosis. A comparative study of host determinants and functions. Biol. Rev. 31, 109.

Prazmowski, A. (1890). Die Wurzelknöllchen der Erbse. Landrw. VersSta. 37, 161.

SchaEde, R. (1940). Die Knöllchen der adventiven Wasserwurzeln von Neptunia oleracea und ihre Bakteriensymbiose. Planta, 31, 1.

Schaede, R. (1941). Untersuchungen über die Wurzelknöllchen von Vicia faba und Pisum sativum. Beitr. Biol. Pfl. 27, 165.

Thimann, K. V. (1936). On the physiology of the formation of nodules on legume roots. Proc. nat. Acad. Sci., Wash. 22, 511.

Thornton, H. G. (1929). The role of the young lucerne plant in determining the infection of the root by the nodule-forming bacteria. Proc. Roy. Soc. B, 104, 481.

Thornton, H. G. (1936). The action of sodium nitrate upon the infection of lucerne root-hairs by nodule bacteria. Proc. Roy. Soc. B, 119, 474.

Thornton, H. G. (1954). The nodule bacteria and their host legumes: some problems that they still present. Sci. Progr. 42, 185.

Thornton, H. G. \& Nicol, H. (1936). Stimulation of root-hair growth in legumes by sterile secretions of nodule bacteria. Nature, Lond. 137, 494.

Viermann, H. (1929). Die Wurzelknöllchen der Lupine. Bot. Arch. 25, 45.

WARD, H. M. (1887). On the tubercular swellings on the roots of Vicia faba. Phil. Trans. B, 178, 539. 
Journal of General Microbiology, Vol. 16, No.2
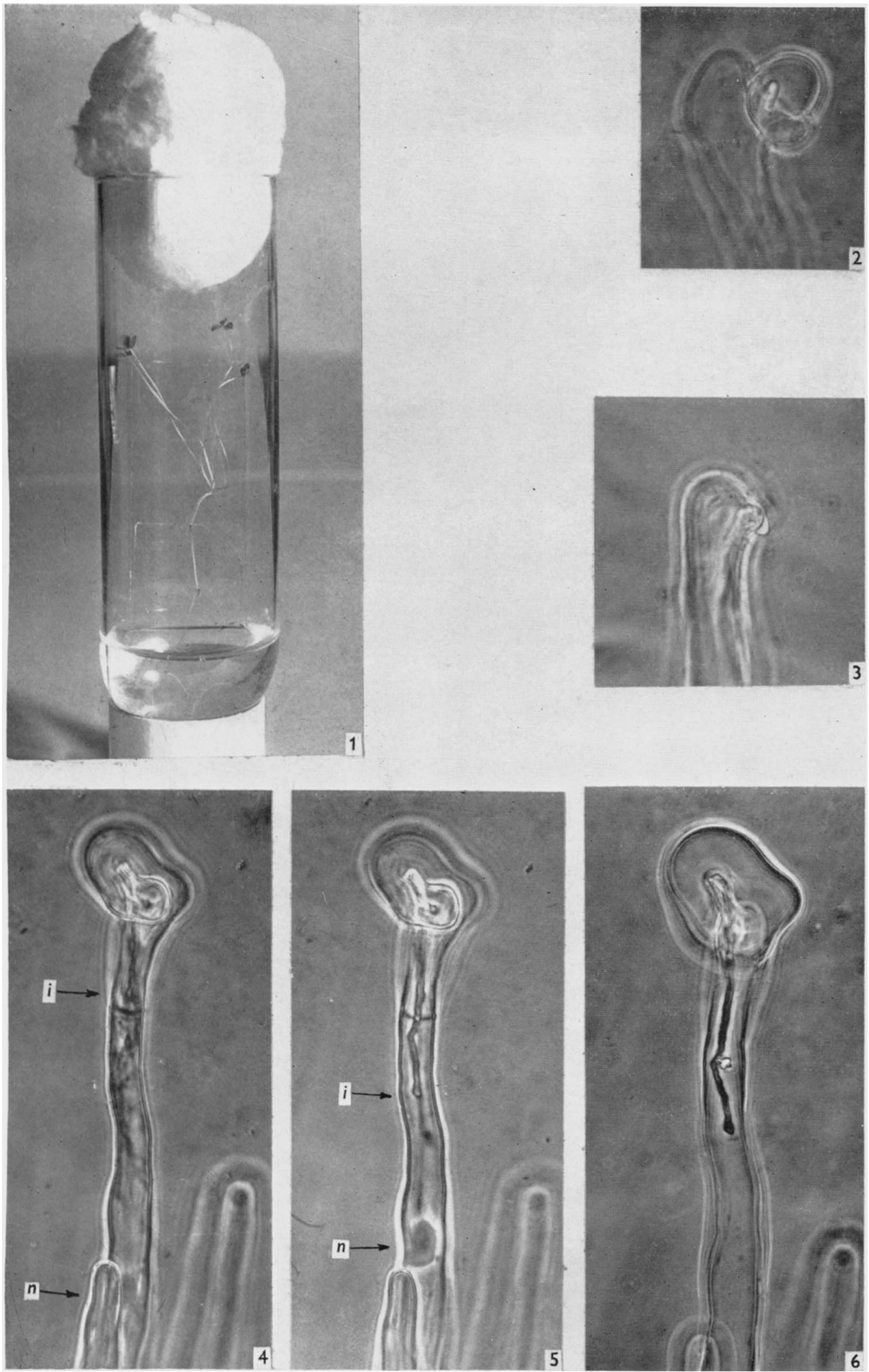

G. Fånafes-Clover root ixfection by rhizobia. Plate 1 
Journal of General Microbiology, Vol. 16, No. 2
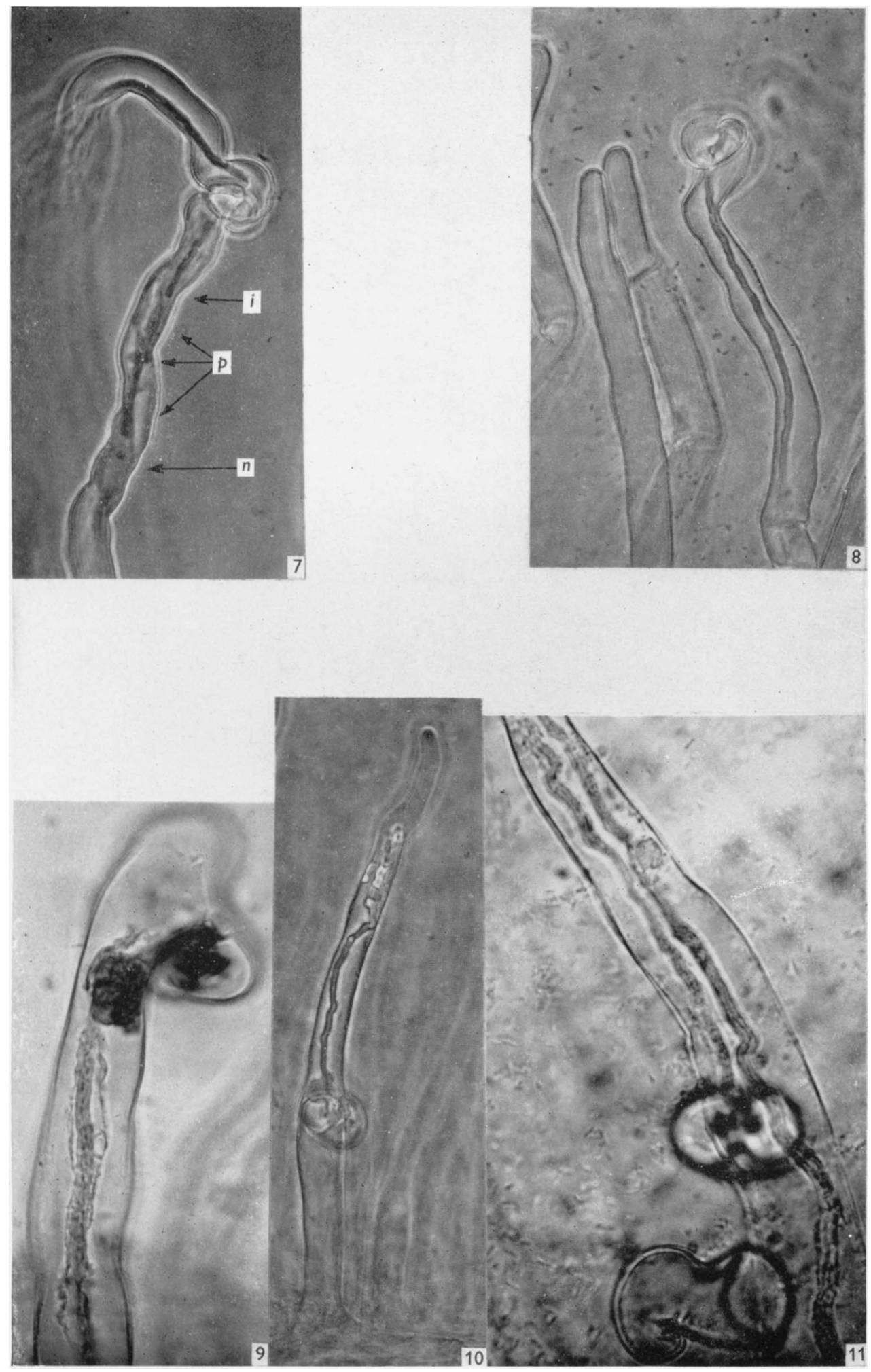

G. Fähraets-Chover boot infection by rhizobia. Plate 2 
Journal of General Microbiology, Vol. 16, No. 2
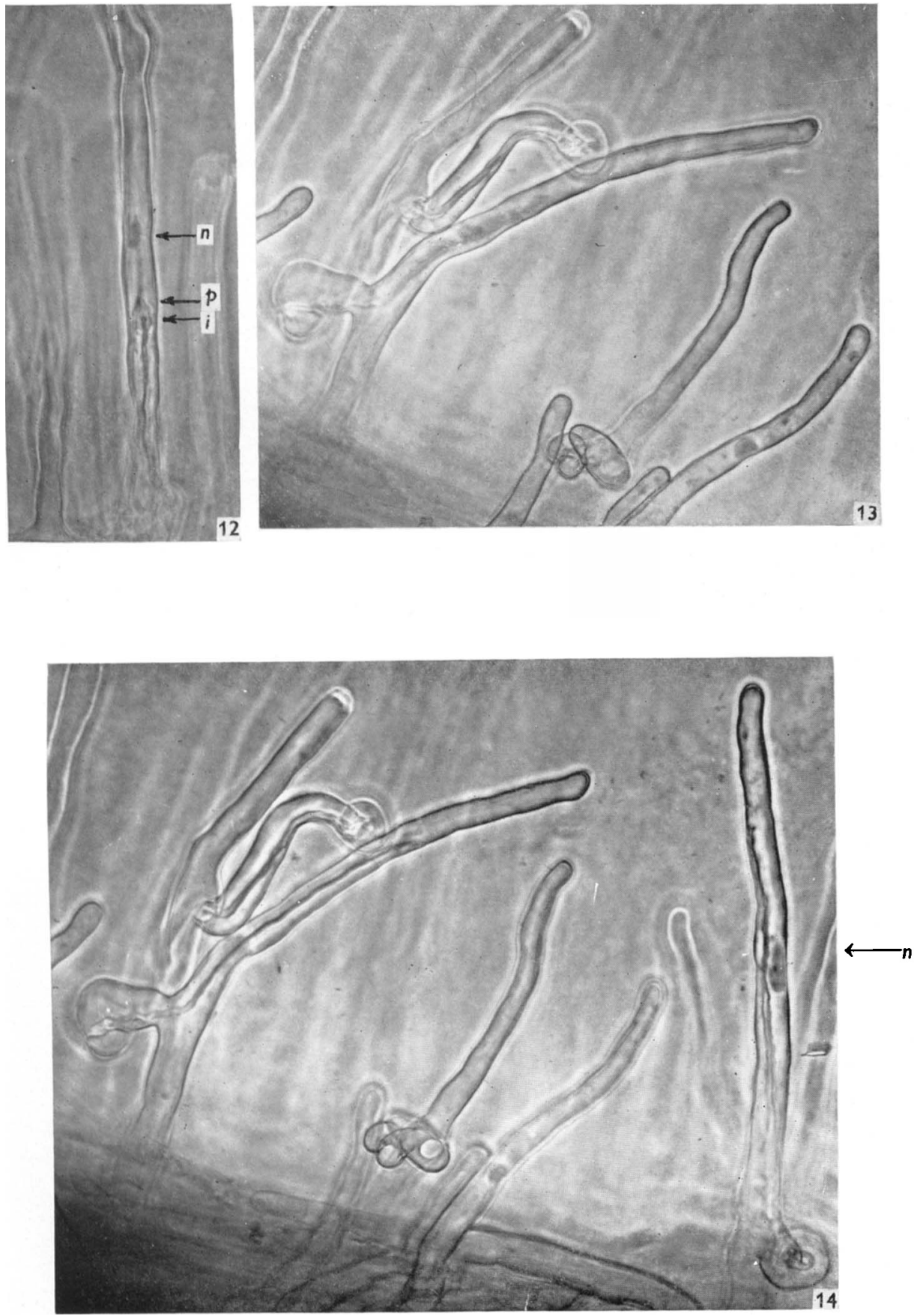

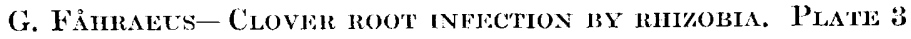





\section{EXPLANATION OF PLATES}

In all plates, $i=$ tip of infection thread, $n=$ nucleus, and $p=$ protoplasm of root hair.

Plate 1

Fig. 1. Culture tube containing slide with a seedling a few weeks old. Nodules have appeared under the cover-slip. $\times 0 \cdot 6$.

Fig. 2. Curled and infected hair with refractile emergence near the tip. Phase contrast, $\times 800$.

Fig. 3. Straight and infected hair with a similar structure. Phase contrast, $\times 900$.

Figs. 4-6. A single root hair photographed 4, 5, and 11 days after inoculation. Phase contrast, $\times c .600$. The tip of the infection thread is almost concealed behind the streaming protoplasm in fig. 4 (4 days). Observations on the day before showed no infection thread, but intense plasmatic activity. No transverse wall had been formed and the nucleus was then located at $i$ in Fig. 4. The wall has later degenerated (Fig. 6).

\section{Plate 2}

Fig. 7. Two hairs bent together, both infected. Photographed $48 \mathrm{hr}$. after inoculation. Phase contrast, $\times 630$.

Fig. 8. Infected root hair and bacterial rods outside the hair. Phase contrast, $\times 630$.

Fig. 9. Root hair with infection thread stained with methylene blue. Photographed in bright field, $\times 900$.

Fig. 10. Infection thread growing from side bulb towards the hair tip. Degenerated nucleus visible just above the entrance bulb. The thread has stopped growing and shows irregular swellings. Phase contrast, $\times 400$.

Fig. 11. Infection thread which has turned near the hair tip and grown back towards the base passing the entrance bulb. Stained with methylene blue, photographed in bright field, $\times 900$.

\section{Plate 3}

Fig. 12. Infection thread growing towards the hair nucleus. Phase contrast, $\times 280$.

Fig. 13. Two adjacent root hairs, one with a normal infection thread, the other probably infected and with actively motile protoplasm in the hair above the side bulb. The nucleus is situated in the protoplasmic strand. 4 days after inoculation. Phase contrast, $\times 400$.

Fig. 14. The same microscopic field, $19 \mathrm{hr}$. later. Three infection threads arising in hair branches, one growing normally into root and two growing towards hair tip. Both of the latter have stopped growing. Phase contrast, $\times 400$.

(Received 14 September 1956) 